\title{
DENSITY CORRECTION FOR GEOPHYSICAL WELL LOGGING INSIDE DRILLING RODS
}

\author{
Wanderson Roberto Pereira ${ }^{1}$, Dionísio Uendro Carlos ${ }^{1}$ and Marco Antonio da Silva Braga²
}

\begin{abstract}
This paper brings the results of the application of a casing correction applied to density logging inside drill rods using a ${ }^{137} \mathrm{Cs}$ source intended to iron ore exploration. A set of runs was performed in a double logging in the same hole, both with and without drilling rods. The recovered density showed above $94 \%$ of adherence with the open hole measured density in valid intervals. The correction made possible to avoid tool wrecking, improving productivity and safety by allowing running density logging tools over the entire drill hole inside rods
\end{abstract}

Keywords: geophysical well logging, iron ore exploration.

RESUMO. Este trabalho traz os resultados da aplicação de uma correção para perfilagem geofísica no interior de uma haste de sondagem utilizando uma fonte de ${ }^{137}$ Cs na exploração mineral de ferrosos. Uma série de perfilagens foram conduzidas em duplicidade em um mesmo furo de sondagem, tanto com a presença de hastes de sondagem como sem estas. A densidade recuperada mostrou $94 \%$ de aderência com a densidade medida sem as hastes nos intervalos válidos. A correção tornou possível evitar sinistro com a ferramenta de perfilagem, aumentando a produtividade e segurança por meio da perfilagem em toda a extensão do furo internamente às hastes de sondagem.

Palavras-chave: perfilagem geofísica, exploração mineral de ferrosos.

\footnotetext{
1VALE, Av. de Ligação, 3580, Prédio 1, Sala Exploração Mineral, Águas Claras, 34000-000 Nova Lima, MG, Brazil. Phone: +55(11) 3251-4201

- E-mails: wanderson.pereira@vale.com; dionisio.carlos@vale.com

2UFRJ, Universidade Federal do Rio de Janeiro, CCMN-IGE0-Departamento de Geologia, Av. Athos da Silveira Ramos, 274, Ilha do Fundão, Sala J2-013, Cidade Universitária, 21941-916 Rio de Janeiro, RJ, Brazil. E-mail: marcobraga@geologia.ufrj.br
} 


\section{INTRODUCTION}

Most of the correction equations for logging inside casing are tailored to oil and gas exploration, thus, it is applied in sedimentary environments in which there is a large database relating lithology and density ranges. Therefore, the long spaced sensor is preferred to take correction measures once the casing influence in the final density is smaller than that read in the long spaced one (Ellis \& Singer, 2008). Once the density ranges in the iron ore exploration are systematically higher, it is rather preferred to use the short spaced sensor in order to measure the influence of the drilling rods density and separate it from the formation density.

Another operational issue to be taken onto consideration is the fact that if one have a logging tool wreck in the oil industry, the abandon procedure can be taken (DeGeare et al., 2003), once the exploitative operations will never reach that point directly, however, the situation in the mineral exploration sector is quite different because it is almost certain that in the future, during the mine live, the wrecking point will be reached as the mine pit advances. For this reason, to run geophysical well logging inside drilling rods can be a suitable solution to minimize the risk of lost-in-hole occurrences in the context of iron ore exploration.

Nevertheless, considering the operational nature of geophysical well logging in iron ore exploration, a density correction tool can maximize the amount of information provided by geological drilling, by logging inside drill rods, allowing running the entire hole without the inconvenience of tool wrecking.

Once iron ore exploration requires a ${ }^{137} \mathrm{Cs}$ radioactive source, the correction must be tailored to this specific source count range, making it different from neutrons correction (Elkington et al., 2006).

With the increase of profiled footage and reducing the risk of lost-in-hole, productivity consequently enhances, allowing that a geophysical well logging in friable lithology has a performance similar to as in compact lithology.

\section{Operational Factors}

In iron ore geological drilling operations, the rock compactness, besides being associated to future planning stages for mining and mineral processing by its compact or friable characteristic, is a definitive factor upon the drilling performance, and friable rocks enable a greater drilling progress rate than the compact ones, increasing costs and execution time.

Besides, the transition from a compact rock to a friable one can be abrupt and present an episodic character, with one or a few occurrences along the borehole, or even a chronic character, presenting a greater frequency variation along the same hole, as shown in Figure 1.

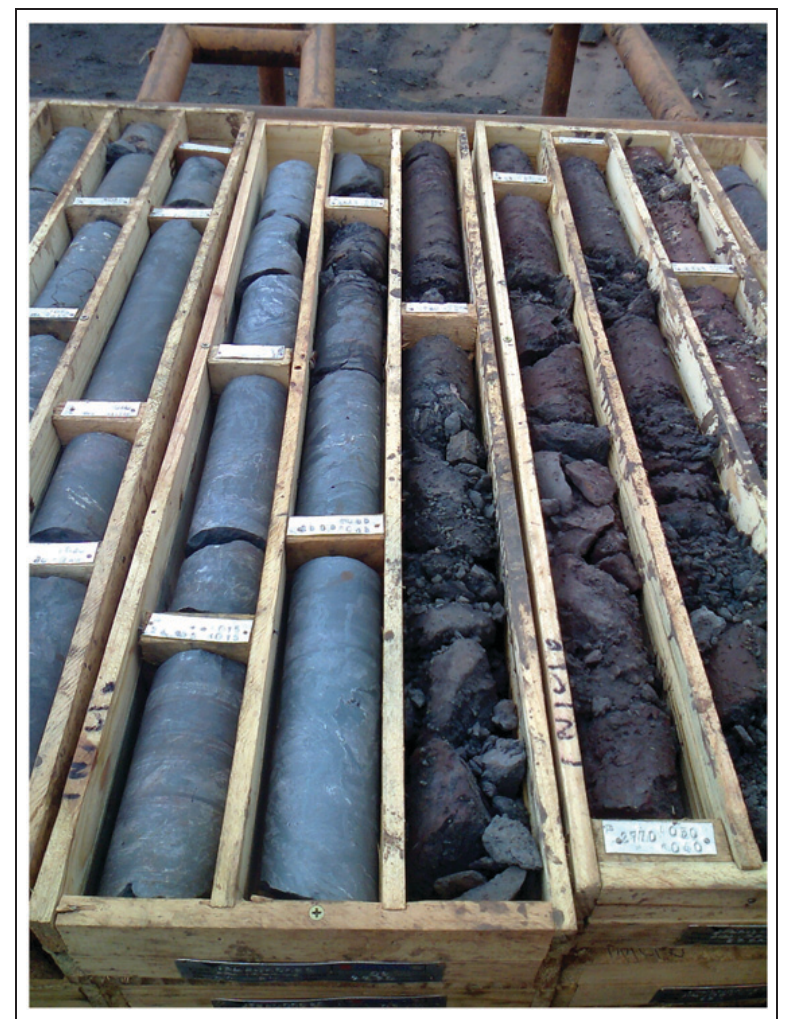

Figure 1 - Core indicating an abrupt changeover from compact lithology (left) to a friable one (right) in a hole.

Due to the compactness and cohesion of each lithology, the drilling rod shall induce a fracturing in the borehole walls. The fracturing is greater for friable lithology and less cohesive rocks, and lesser for compact and greater cohesion lithology, as in Figure 2.

The fracturing induced by the drilling activity may cause collapses in the borehole walls after the removal of drilling rods, resulting in a hole locking which makes impossible to run geophysical well logging over the total depth drilled.

If the collapse occurs during the geophysical profiling activity, it may cause a locking of the geophysical tool in the borehole. Figure 3 presents a borehole in poor conditions after the removal drilling tool, creating an uncertain condition for the geophysical well logging activity.

Even if there is not a hole locking, friable lithology have an irregularity in hole walls, which may induce proportional variations in density values (Darling, 2005), whether in variation of unconsolidated materials or in diameter variations arising from the roughness, as in Figure 4. 


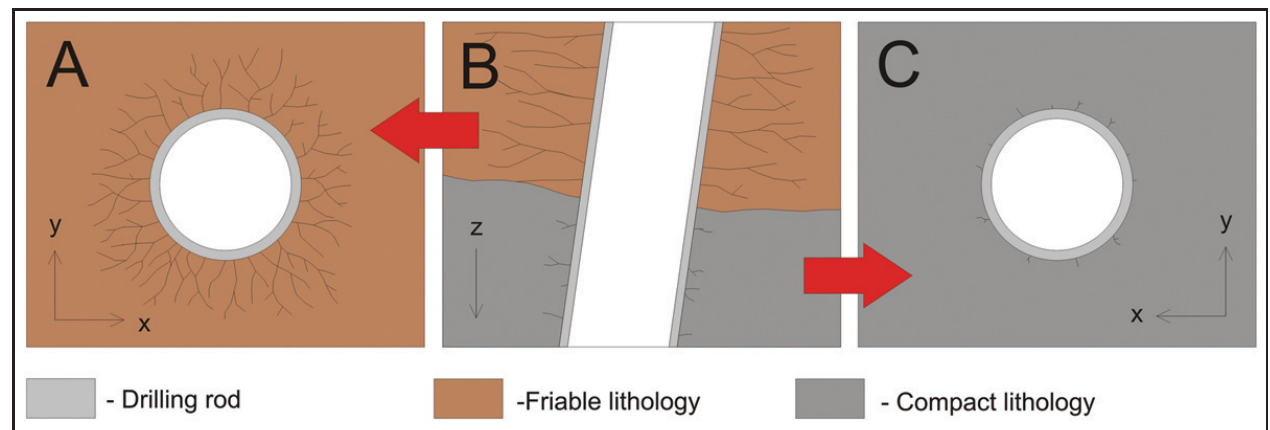

Figure 2 - Illustration of a borehole in a changeover from friable lithology to a compact one, and the respective induced fracturing. A) Hole plan view - friable lithology; B) Increasing section of a borehole stretch; C) Hole plan view - compact lithology.

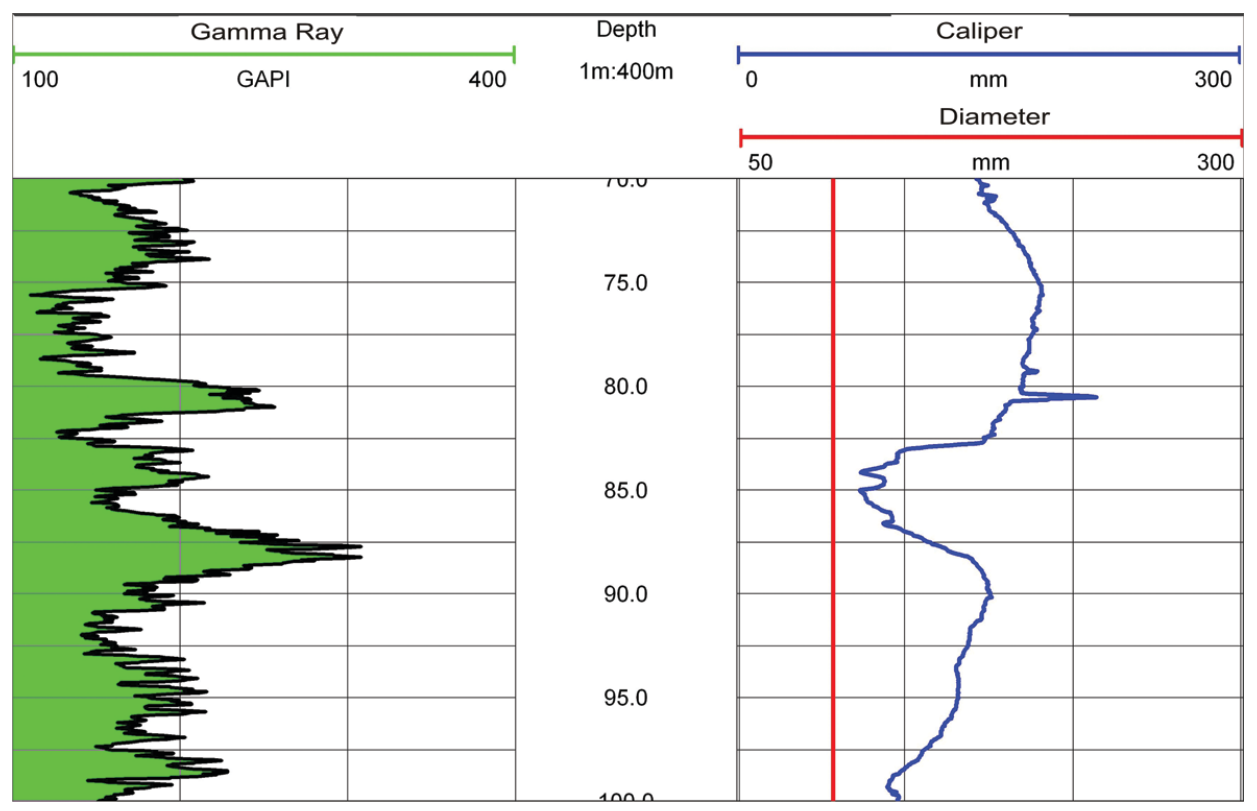

Figure 3 - Borehole with collapse and buildup of collapsed material in $85 \mathrm{~m}$. In green, the natural gamma counts; in blue, the variation of internal diameter in borehole; in red, the nominal diameter.

An enabling alternative for geophysical well logging with friable material intervals consists in running the geophysical tool inside drilling rods, ensuring the integrity of borehole walls during the logging and the subsequent record of total logged footage in the borehole.

To do so, it is required to perform the geophysical well logging at the end of drilling activity and before the removal of drilling rods, with the probe still positioned at the drilling area, as shown in Figure 5.

The rod geophysical profiling has the advantage of allowing the tool to slide over a regular surface, and also a greater exploitation of logged footage due to containing potential collapses, however, the drilling rod, by itself, represents an uncertainty factor because of its density being higher than the range of densities expected for iron mineralization.

In order to enable such practice, it is required knowing the effects caused by this acquisition geometry, considering the influence of the rod in density measurements, as well as compensating or correcting such influence.

\section{Density Measurements inside Drilling Rods}

Density measurements by conventional gamma-gamma well logging (Telford et al., 1990), can be acquired by means of a radioactive source and two sensors with different spacing from the source, all coupled to a profiling probe which is introduced inside the borehole in such a way to allow a coupling between sensors and the hole wall, as in Figure 6. 


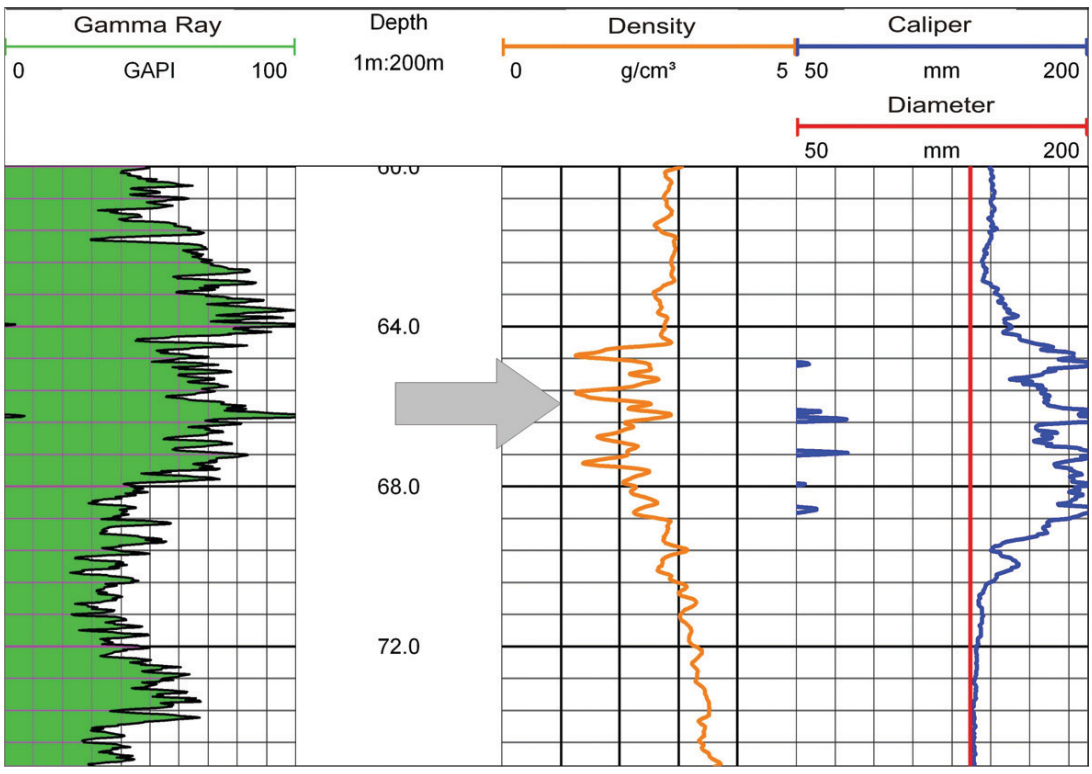

Figure 4 -Density variation (in orange) with the hole wall roughness. The gray arrow indicates a region of density variation due to hole enlargement. In green, the natural gamma counts; in blue, the variation of internal diameter inside the borehole; in red, the nominal diameter.

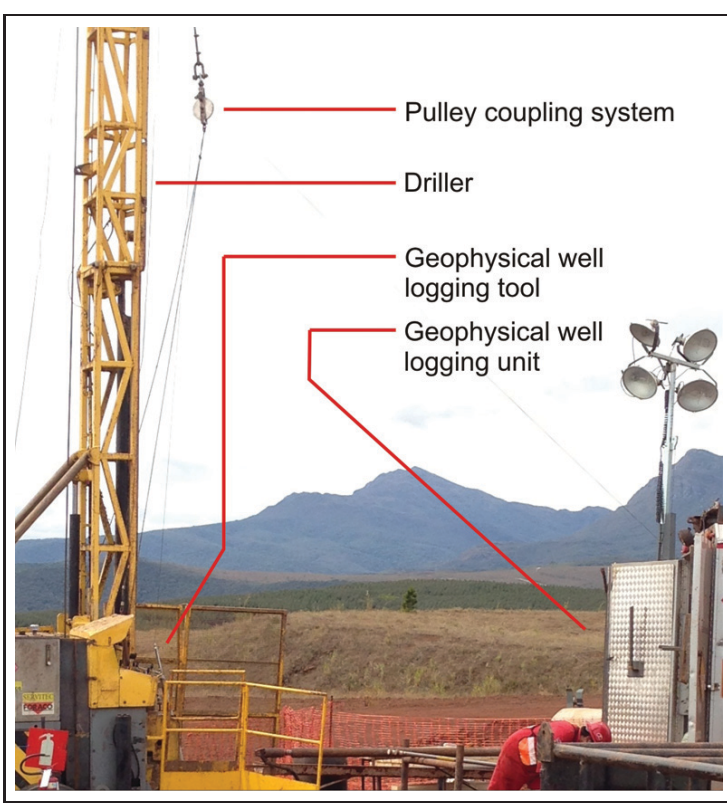

Figure 5 - Geophysical well logging tool coupling system.

In Figure 6 it is possible to note a probable representation of the interaction between gamma radiation and rock mass, considering this interaction being approximate, through a path in the dimension of spacing between source and sensors.

Such interaction follows the next equation:

$$
N=N_{0} e^{-\mu \rho x}
$$

where $N$ = gamma radiation count read by sensor; $N_{0}=$ radiation count emitted by source; $\mu=$ mass absorption coefficient; $\rho=$ rocky mass density; and $x=$ spacing between source and sensor (Ellis \& Singer, 2008).

From (1) we can infer that, for densities greater than 1.0 $\mathrm{g} / \mathrm{cm}^{3}$, the API (American Petroleum Institute Units) counts has an inverse exponential proportion in relation to the density, as in Figure 7.

For the case of drilling rod well logging, the acquisition geometry described in Figure 6 starts being conditional by the presence of the drilling rods between geophysical well logging tool and rock mass, as in Figure 8.

Inserting a drilling rod, the considered average distance between source and sensors turns to have a distinct component, with a drilling rod density and a length equivalent to the drilling rod thickness.

Thus, the attenuation of gamma radiation during the acquisition now has two different components, one of them with the rock mass, conducted by (1), and the other one with the drilling rod, and can be represented by the Equation 2 .

$$
N_{1}=N_{0} e^{-\mu \rho_{h} h}
$$

where $N_{1}=$ gamma radiation count which crosses the rod; $N_{0}=$ radiation count emitted by source; $\mu=$ mass absorption coefficient; $\rho_{h}=$ drilling rod density; and $h=$ rod thickness. 


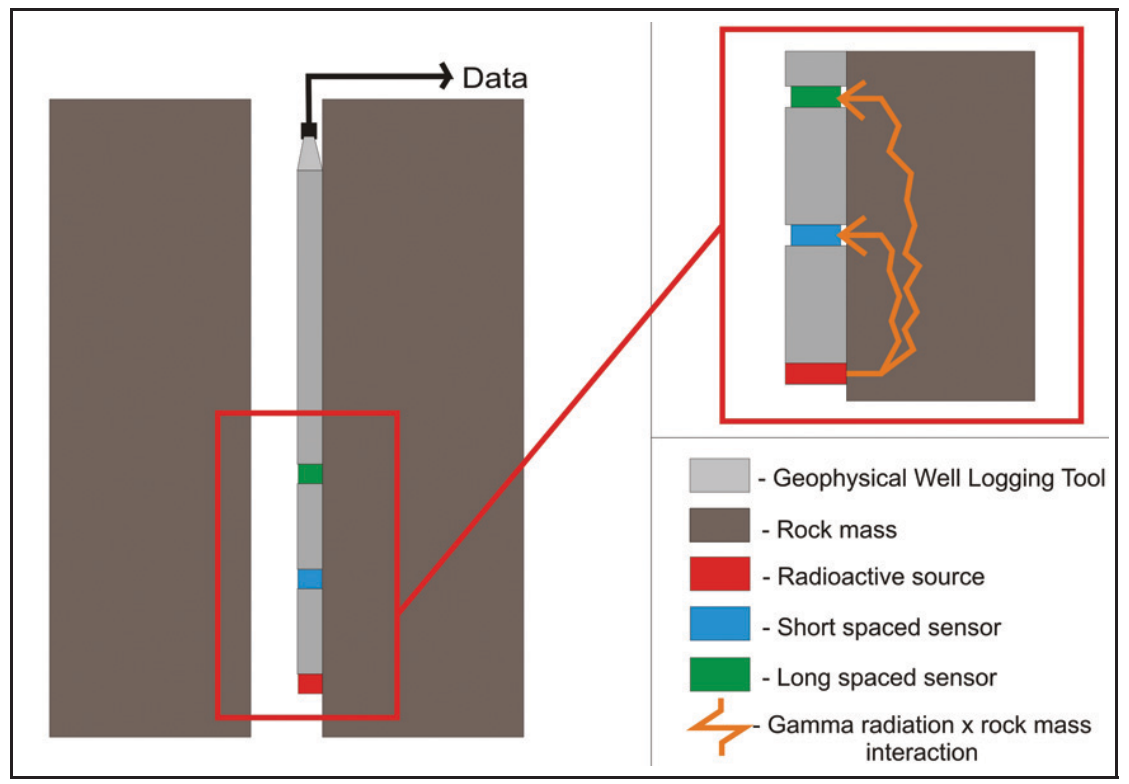

Figure 6 - Acquisition geometry of gamma-gamma well logging data with detailing of gamma radiation and rock mass interaction.

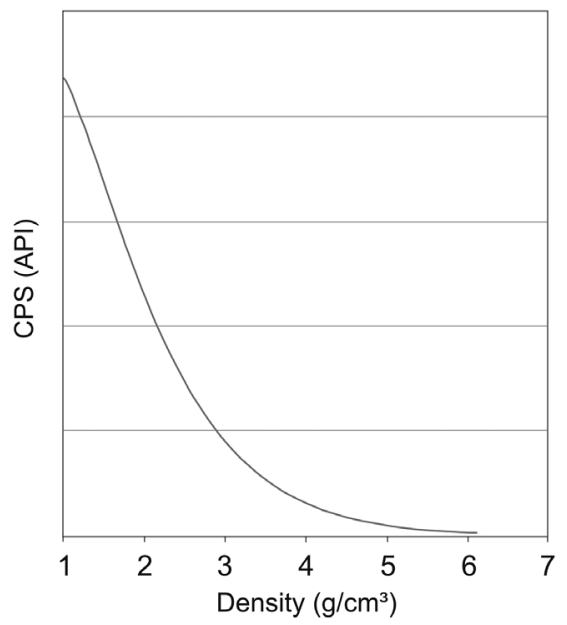

Figure 7 - Relation between API count and density for a ${ }^{137}$ Cs source.

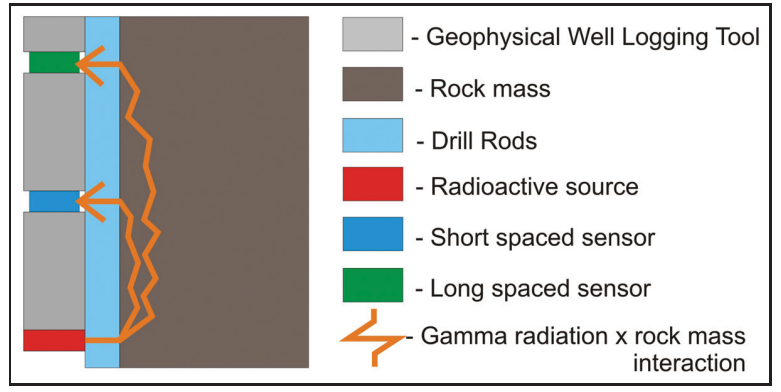

Figure 8 - Acquisition geometry regarding the presence of metallic rod. 


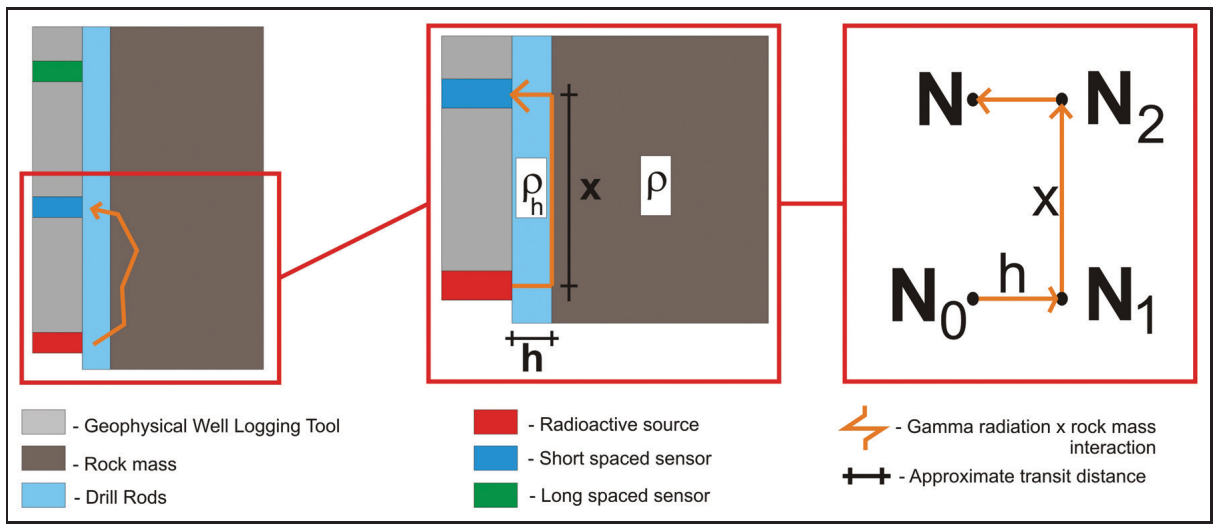

Figure 9 - Simplified acquisition geometry, where $\rho_{h}=$ rod density; $h=$ rod thickness; $\rho=$ formation density; $x=$ sensor source distance; $N=\mathrm{API}$ counting at each point.

Considering the acquisition geometry displayed in Figure 6 , we can distinguish two ranges with different densities, being them the range with a rod thickness $h$, whose density $\rho_{h}$ corresponds to the rod density, and the range with a rock wall length $x$, whose density $\rho$ corresponds to the rock mass density, according to Figure 9.

In Figure 9, based on the relative attenuation of gamma radiation described in (1) and (2), it is possible to relate different API counting values in different points of the design, due to the presence of the rod, as well as the rock mass, into the approximate path covered by the gamma radiation, from source to sensor. Considering $N_{0}=$ direct counting (at source), the attenuation caused by the rod will decrease this value to a counting $N_{1}=\left(N_{0}\right.$ counting lessened by the rod).

The same will occur at the point where the gamma radiation, with initial counting $N_{1}$, transforms into $N_{2}$ (counting after the particles travel the $x$ distance thru the rock mass), which density $\rho$ one intends to calculate.

Finally, the sensor will record a density $\rho_{1}$ (composition between stone and rod density), conditioned by the acquisition geometry.

\section{METHODOLOGY}

Considering a bulk density $\rho_{1}$ read by the sensor in a hole with drilling rods, from (1), we have:

$$
\rho_{1}=\frac{-\ln \left(N / N_{0}\right)}{\mu x}
$$

Thus considering the acquisition geometry described in the Figure 9, we may distinguish three interaction steps with regards to the interaction of the radiation with the drilling rod, while the first one is described by (2). The second step, to which the gamma radiation API count will be mitigated by the bulk formation, with density $\rho$, results in:

$$
N_{2}=N_{1} e^{-\mu \rho x}
$$

Lastly, the third step, in which $N_{2}$ count will be once more lessened by the rod, resulting in the $N$ bulk counting, related to the $\rho_{1}$ bulk density read by the sensor:

$$
N=N_{2} e^{-\mu \rho_{1} h}
$$

By substituting (2) and (4) in (5), we have:

$$
N=\left[\left(N_{0} e^{-\mu \rho_{h} h}\right) e^{-\mu \rho x}\right] e^{-\mu \rho_{1} h}
$$

Equivalent to:

$$
N=N_{0} e^{-\mu \rho x} e^{-\mu h\left(\rho_{1}+\rho_{h}\right)}
$$

Isolating densities, we may obtain:

$$
\frac{-\ln \left(N / N_{0}\right)}{\mu x}=\rho+h\left(\rho_{1}+\rho_{h}\right) / x
$$

Replacing (3) in (8), and isolating the desired $\rho$ density, the result is:

$$
\rho=\rho_{1}-h\left(\rho_{1}+\rho_{h}\right) / x
$$

\section{RESULTS}

In order to check the correction equation, it was applied to data from a drilling hole to which a geophysical profiling was performed in two different run-offs, the first using drilling rod (cased hole), and the second without rod (open hole), resulting in the Figure 10 chart.

Based on residues observed in the chart from Figure 10 (blue line), we may infer that in the drilling hole in question, for the range where there is wall collapse, the residues are systematically 


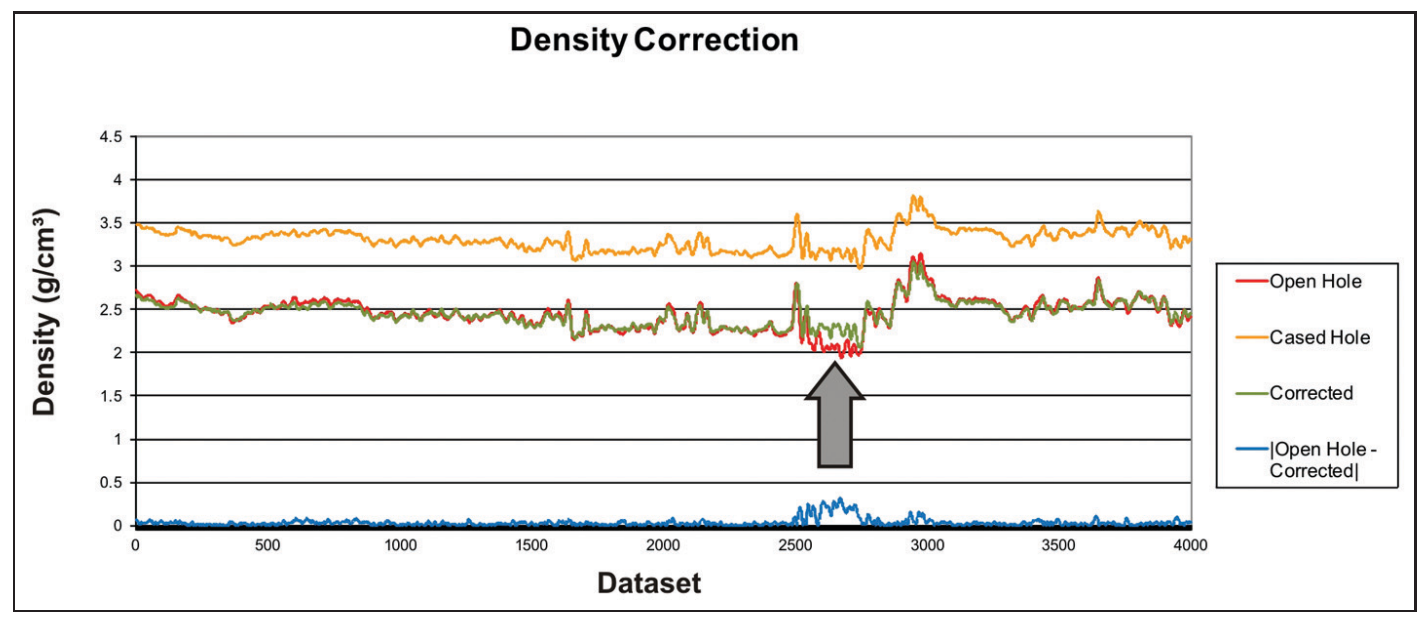

Figure 10 - Application of correction equation to density data from cased hole compared with data from open hole. In red, density values measured in open hole; in yellow, density values measured in cased hole; in green, density values obtained from the cased hole, corrected for the rod influence; in blue, the residues. The gray arrow indicates borehole wall collapse, caused by the drilling rod removal maneuver.

higher, consisting in an indicator of modifications in the drilling hole wall conditions after the removal of drilling rods.

Furthermore, it is possible to identify an increase in residue values where densities reach their upper value, denoting that the correction may have greater adherence in lower density ranges, or in closed ranges.

The chart also suggests a seeming trend between corrected density values and the open hole density values, increasing the upper density values and decreasing the lower ones for the data in question without significant impact in residue values.

\section{CONCLUSION}

Analyzing results obtained in the Figure 10, we may conclude that, for the hole in question, correcting densities is useful since it recovers with good approximation the bulk density values distorted by the presence of drilling rods.

In the event that the collapse in the drilling hole wall, pointed by the gray arrow in the Figure 10, had been pre-existent, it could be detected by the quality control though analysis of difference between density measurements recorded by short and long spaced sensors.

Such factor corroborates the increase of residues related to greater recorded density values, showing the possibility of a confidence range where the corrections are more effective.

Considering the gamma radiation attenuation curve including the increase of density displayed in Figure 7 , a confidence range may be outlined for the density measures, to which the correction imposes a displacement, as the measure using drilling rod fol- lows the same API count $\times$ density relationship, which remains after applying the correction.

Thereby, a difference in densities surrounding a high density value recorded in measurements of cased holes implies a very subtle difference in counts, which may exceed the confidence range of the API count $\times$ density relationship.

Similarly, very low density values, measured in cased holes, shall be forced in the confidence range, whereas the rock density itself may lie before such range.

Consequently, a reduced confidence range in relation to the observed for open hole density measurements may exist for very low densities, like in sedimentary coal exploration environments, or very high, greater than those found in ferrous exploration.

As control measure, a correlation between density logs and the geological description of drilling holes may be used, as well as conventional density data and data from petrophysical scanners, in addition to the quality control of gamma-gamma density values.

\section{ACKNOWLEDGEMENTS}

The authors thank to VALE Iron Ore Exploration for the support and founding of this project.

\section{REFERENCES}

DARLING T. 2005. Well Logging and Formation Evaluation. Elsevier. Burlington, USA. 335 pp.

DeGEARE J, HAUGHTON D \& McGURK M. 2003. The Guide to Oilwell Fishing Operations. Elsevier. Waltham, USA. 200 pp. 
ELKINGTON PAS, PEREIRA CA \& SAMWORTH JR. 2006. A Novel Cased Hole Density-Neutron Log - Characteristics and Interpretation. Conference Paper. In: Asia Pacific Oil \& Gas Conference and Exhibition. Adelaide, Australia. 7 pp.
ELLIS DV \& SINGER JM. 2008. Well Logging for Earth Scientists. 2nd ed., Elsevier. Dordrecht, Netherlands. 692 pp.

TELFORDWM, GELDART LP \& SHERIFFRE. 1990. Applied Geophysics. Cambridge University Press. New York, USA. 792 pp.

Recebido em 2 junho, 2015 / Aceito em 23 fevereiro, 2016

Received on June 2, 2015 / Accepted on February 23, 2016

\section{NOTES ABOUT THE AUTHORS}

Wanderson Roberto Pereira. Bachelor in Geophysics from IAG/USP. Currently, works at VALE Ferrous Mineral Exploration. Develops studies related to QA/QC, processing and interpretation of geophysical logs applied to iron ore exploration. Main interests: geophysical well logging, gravity gradiometry, geophysical rock mass characterization.

Dionisio Uendro Carlos. Bachelor and Master Degrees in Geophysics at IAG/USP. PhD in Geophysics at Observatório Nacional/MCTI/Colorado School of Mines. Was a visiting researcher at the Geophysics Department, Colorado School of Mines (USA) and is, currently, coordinator of VALEFerrous Mineral Exploration Geophysics section. Main interests: gravity gradiometry inversion and modeling, physical properties of rocks.

Marco Antonio da Silva Braga. PhD and Masters in Geology, with emphasis on Applied Geophysics from the Universidade Federal do Rio de Janeiro/Colorado School of Mines. Specialized in geophysical methods applied to exploration of iron ore. Main interests: gravity gradiometry, iron ore exploration. 